\title{
Qualidade microbiológica de queijo-coalho comercializado em Aracaju, SE
}

[Microbial quality of "coalho" cheese commercialized in Aracaju, SE]

\author{
R.F. Santana ${ }^{1,2}$, D.M. Santos ${ }^{1}$, A.C.C. Martinez ${ }^{1}$, Á.S. Lima ${ }^{1,2} *$ \\ ${ }^{1}$ Universidade Tiradentes - Aracaju, SE \\ ${ }^{2}$ Instituto de Tecnologia e Pesquisa \\ Av. Murilo Dantas, 300 \\ 49032-490 - Aracaju, SE
}

\section{RESUMO}

Determinou-se a ocorrência de Staphylococcus aureus, Salmonella spp. e de microrganismos indicadores de contaminação fecal em queijos-coalho comercializados em 15 pontos de venda do Mercado Central de Aracaju, $\mathrm{SE}$, durante quatro meses. Dezesseis amostras (26,7\%) foram positivas para Salmonella spp. e $28(46,7 \%)$ positivas para estafilococos coagulase positiva. Quanto à contaminação por coliformes totais, $56(93,3 \%)$ das amostras apresentaram valores entre $8,0 \times 10^{2}$ e $1,23 \times 10^{4} \mathrm{NMP} / \mathrm{g}$, e de $2,72 \times 10^{2}$ a $1,12 \times 10^{3} \mathrm{NMP} / \mathrm{g}$ para coliformes termotolerantes. Estes valores não atenderam à legislação brasileira para queijo-coalho e as amostras analizadas podem ser classificadas como impróprios ao consumo humano.

Palavras-chave: queijo-coalho, Salmonella, coliformes, Staphylococcus coagulase positivo

\section{ABSTRACT}

The occurrence of Staphylococcus aureus, Salmonella spp., and microorganisms indicators of fecal contamination in "coalho"cheese commercialized in 15 retail store at the Central Market of Aracaju, SE during four months was determined. Sixteen samples (26.7\%) were positive for Salmonella spp. and 28 (46.7\%) for coagulase positive staphylococci. In relation to contamination by total coliforms, 56 samples (93.3\%) presented values from $8.0 \times 10^{2}$ to $1.23 \times 10^{4} \mathrm{NMP} / \mathrm{g}$; and for thermal tolerant coliforms, from $2.72 \times 10^{2}$ to 1.12 $x 10^{3} \mathrm{NMP} / \mathrm{g}$. These values are not acceptable for the Brazilian legislation for "coalho" cheese. This indicates that the analyzed products were inappropriate to the human consumption.

Keywords: “coalho” cheese, Salmonella, coliforms, Staphylococcus

\section{INTRODUÇÃO}

O queijo obtido por coagulação do leite por meio de coalho, complementada ou não pela ação de bactérias lácteas selecionadas, classificado como queijo de média a alta umidade, é denominado de queijo-coalho (Brasil, 1996). No Nordeste do Brasil a maior parte da produção de queijocoalho é obtida em pequenas e médias queijarias, as quais movimentam, mensalmente, algo em torno de 10 milhões de reais, o que sinaliza essa atividade como importante no âmbito social e econômico (Perry, 2004).

Em algumas localidades, o leite ainda é obtido sob condições higiênico-sanitárias deficientes e, em conseqüência, apresenta elevado número de microrganismos, o que constitui um risco à saúde da população, principalmente quando consumido sem tratamento térmico. Dessa forma, para o leite e seus derivados, cuidados higiênicos desde a ordenha até a obtenção do produto final devem ser empregados (Catao e Ceballos, 2001). O queijo-coalho, por ser elaborado em pequenas propriedades rurais ou em pequenas indústrias, que não adotam as boas práticas de fabricação, não apresenta segurança microbiológica e padronização de qualidade. A contaminação microbiana desse produto assume destacada relevância para a saúde pública, pelo potencial risco de causar doenças transmitidas pelo alimento (Feitosa et al., 2003).

Recebido em 28 de fevereiro de 2008

Aceito em 20 de outubro de 2008

*Autor para correspondência (corresponding autor)

e-mail: álvaro_lima@itp.org.br 
Durante o processo de produção, elaboração, transporte, armazenamento e distribuição, a contaminação microbiana dos alimentos é indesejável e, inclusive, nociva. Esse aspecto é encarado com tal rigor que para se conhecer a existência de possíveis deficiências higiênicas, que implicariam em contaminação do alimento, buscase averiguar a presença de microrganismos indicadores de má qualidade higiênica e de microrganismos patogênicos (Salotti et al., 2006).

Vários estudos sobre a qualidade microbiológica de queijo-coalho relataram ocorrência de microrganismos patogênicos e contagem de microrganismos deterioradores em números que excedem, às vezes, os limites estabelecidos pela legislação. Dentre as bactérias patogênicas observadas destacam-se Salmonella spp., Escherichia coli e Staphylococcus aureus (Cavalcante et al., 2007).

Salmonella spp., bactéria responsável por casos de toxinfecções alimentares, é comumente observada em queijo-coalho, normalmente é encontrada no trato intestinal de animais domésticos e silvestres, especialmente aves e répteis e tem como principal veículo de disseminação os alimentos e a água (Ávila e Gallo, 1996; Feitosa et al., 2003)

Contagens elevadas de microrganismos do grupo coliformes são freqüentemente observadas no queijo-coalho, sugerindo que foram produzidos em condições de higiene insatisfatória. A presença de coliformes fecais ou termotolerantes em alimento é indicativa de que houve contato direto com material fecal (Duarte et al., 2005). S. aureus é um dos agentes patogênicos mais comuns, responsável por surtos de intoxicação de origem alimentar pela enterotoxina estafilocócica (Cunha Neto et al., 2002).

A precariedade higiênico-sanitária da cadeia produtiva e da comercialização de queijo-coalho, e da tradicionalidade do produto na culinária nordestina e especialmente em Sergipe, motivou este estudo que teve como objetivo avaliar a ocorrência de Staphylococcus aureus, Salmonella spp. e microrganismos indicadores de contaminação fecal no queijo-coalho vendido na cidade de Aracaju, Sergipe.

\section{MATERIAL E MÉTODOS}

Foram analisadas 60 amostras de queijos-coalho, coletadas aleatoriamente de todos os estabelecimentos que comercializam (15) esse produto no Mercado Central da cidade de Aracaju, SE, no período de agosto a novembro de 2007. As amostras foram fracionadas, identificadas, pesadas na embalagem comercial originaria do próprio local de venda, acondicionadas em caixas isotérmicas contendo gelo e transportadas, em seguida, até o laboratório de pesquisa em alimentos para análise imediata. Uma faca de aço inoxidável esterilizada foi utilizada para abrir uma fenda na amostra do queijo, de onde se retirou, com auxílio de um estilete, previamente flambado, as alíquotas de queijo-coalho para análise microbiológica (Silva et al., 1997).

$\mathrm{Na}$ quantificação de coliformes totais e termotolerantes, utilizaram-se alíquotas de $25 \pm 0,2 \mathrm{~g}$ diluídas em solução salina peptonada $0,1 \%$ até a obtenção de soluções $10^{-1}$ a $10^{-6}$. O teste presuntivo foi realizado em série de cinco tubos contendo caldo lauril sulfato triptose, incubados em estufa a $35-37^{\circ} \mathrm{C}$, por $24-48 \mathrm{~h}$. O caldo presente nos tubos positivos foi semeado em caldo verde brilhante bile $2 \%$ (VBBL) e incubado a $35^{\circ} \mathrm{C}$, durante $24-48 \mathrm{~h}$, para confirmação de coliformes totais, e semeado em tubos contendo caldo E. coli (EC), incubados a $45,5^{\circ} \mathrm{C}$, por $24-48$ horas, para confirmação de coliformes termotolerantes (Vanderzant e Splittstoesser, 1992).

Para a detecção de $S$. aureus, foram utilizadas alíquotas de $25 \pm 0,2 \mathrm{~g}$ diluídas em água salina peptonada $0,1 \%$ até a obtenção de soluções de diluição $10^{-1}$ a $10^{-3}$. De cada uma das diluições transferiu-se $0,1 \mathrm{ml}$ para placa contendo ágar manitol salgado, as quais foram incubadas a $35^{\circ} \mathrm{C}$ por $48 \mathrm{~h}$. Em seguida, procedeu-se a contagem presuntiva do número de colônias que apresentavam características típicas: colônias circulares, pequenas (máximo 1,5mm em diâmetro), lisas, convexas, com bordas perfeitas e massa de células esbranquiçada. A verificação microscópica da morfologia das células isoladas foi realizada pelo método de Gram. As células que se apresentaram como cocos Gram-positivos, agrupados em forma de cacho, foram submetidas às provas de catalase e DNAase para contagem confirmativa de $S$. aureus (Koneman et al., 1999).

Para a detecção de Salmonella spp., uma alíquota de $25 \pm 0,2 \mathrm{~g}$ foi diluída em caldo lactosado e incubada a $35^{\circ} \mathrm{C}$ por $18-20 \mathrm{~h}$ (pré-enriquecimento). Posteriormente, volumes de $1 \mathrm{ml}$ foram transferidos para tubos contendo $10 \mathrm{ml}$ de caldo selenito cistina e caldo tetrationato e incubados a $35^{\circ} \mathrm{C}$ (enriquecimento seletivo). Após 24h, foram realizados repiques em placas de ágar entérico de Hectoen (HE), ágar bismuto sulfito (BS) e ágar 
xilose lisina desoxiciolato (XLD), e incubação a $35^{\circ} \mathrm{C}$ por $18-24 \mathrm{~h}$. Colônias típicas, reisoladas em tubos inclinados de ágar lisina ferro (LIA) e ágar tríplice açúcar ferro (TSI), foram incubadas a $35^{\circ} \mathrm{C}$ por $18-24 \mathrm{~h}$. Os microrganismos isolados foram submetidos à identificação bioquímica: testes de urease, de indol, de fermentação da lactose e sacarose, de vermelho de metila e Voges-Proskauer, de citrato e de descarboxilação da lisina em caldo. Os resultados foram expressos como amostras com presença ou ausência de Salmonella spp.

\section{RESULTADOS E DISCUSSÃO}

Os resultados das análises microbiológicas são apresentados na Tab. 1. Os valores encontrados para coliformes totais e termotolerantes para as 60 amostras de queijo-coalho, variaram de 15,4 e 4,1 vezes entre os pontos máximos e mínimos, respectivamente.

Tabela 1. Avaliação microbiológica de queijo-coalho comercializado no Mercado Central de Aracaju, SE

\begin{tabular}{lcc}
\hline \multicolumn{1}{c}{ Microrganismo } & Contagem & Valores \\
\hline & Mínimo & $8,00 \times 10^{2}$ \\
Coliformes totais (NMP/g) & Médio & $1,07 \times 10^{3}$ \\
& Máximo & $1,23 \times 10^{4}$ \\
Coliformes termotolerantes (NMP/g) & Mínimo & $2,72 \times 10^{2}$ \\
& Médio & $8,58 \times 10^{2}$ \\
Estafilococos coagulase positiva (UFC/g) & Máximo & $1,12 \times 10^{3}$ \\
& Mínimo & $1,87 \times 10^{5}$ \\
Salmonella sp. $(\mathrm{em} 25 \mathrm{~g})$ & Médio & $6,30 \times 10^{5}$ \\
& Máximo & $3,54 \times 10^{5}$ \\
& Ausência & $73,33 \%$ \\
\hline
\end{tabular}

A legislação brasileira (Brasil, 2001) apresenta limite de tolerância de coliformes termotolerantes de $5,0 \times 10^{2} \mathrm{NMP} / \mathrm{g}$ de amostra. Com base neste limite, verifica-se que $93,3 \%$ dos queijos analisados não estavam aptos à comercialização e, conseqüentemente, ao consumo humano. Os valores encontrados assemelham-se aos apresentados por Loguercio e Aleixo (2001). Esses autores observaram que $93,3 \%$ dos queijos-de-minas frescal artesanais, comercializados na cidade de Cuiabá, MT, estavam fora dos padrões da legislação brasileira, demonstrando que a falta de higiene na cadeia do queijo é inerente ao tipo e à região de comercialização. Rocha et al. (2006) observaram que $61 \%$ do queijo-de-minas frescal, comercializado em supermercados de São Paulo, apresentavam contagem de E. coli acima da recomendada pela legislação. Na Fig. 1, apresenta-se a distribuição da contagem de coliformes termotolerantes nos queijos analisados e, observa-se que, $80 \%$ deles apresentavam contagem microbiana para coliformes termotolerantes acima de 8,0 $\mathrm{x} 10^{2} \mathrm{NMP} / \mathrm{g}$. Essa alta contagem microbiana pode ser atribuída às condições higiênicosanitárias da produção e da comercialização desse produto. Feitosa et al. (2003) observaram baixa contagem para coliformes termotolerantes (36,4\% das amostras com 3-7NMP/g), entretanto a contagem para coliformes fecais foi acima de $100 \mathrm{NMP} / \mathrm{g}$ em $72,7 \%$ das amostras, para queijos comercializados no Rio Grande do Norte.

Resultados apresentados por Cabral (1993), em análise de 50 amostras de queijo-coalho na cidade de João Pessoa, PB, demonstraram que 37 amostras foram positivas para $S$. aureus, com contagem média de $1,2 \times 10^{5} \mathrm{UFC} / \mathrm{g}$. Sabioni et al. (1994), em levantamento realizado com 30 amostras de queijo-de-minas frescal na cidade Ouro Preto, MG, encontraram resultados positivos para $S$. aureus, com contagem de até $10^{8} \mathrm{UFC} / \mathrm{g}$. Assumpção et al. (2003), ao estudarem as fontes de contaminação por $S$. aureus no processo produtivo de queijo-prato, verificaram que a presença desses microrganismos nas mãos e antebraço dos manipuladores foi a responsável pela recontaminação do queijo, pois ocorreu em etapas posteriores à inativação dos microrganismos por pasteurização. Essa observação pode ser utilizada para explicar a alta incidência de $S$. aureus nas amostras de queijocoalho estudadas. 


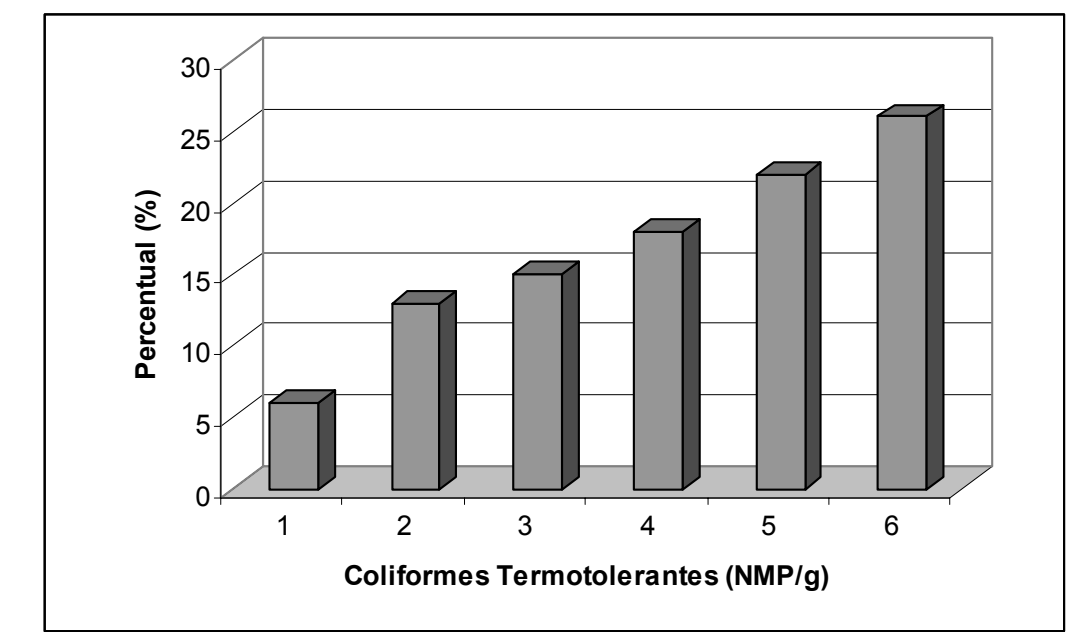

$1=2,72 \times 10^{2} ; 2=5,6 \times 10^{2} ; 3=6,8 \times 10^{2} ; 4=8,0 \times 10^{2} ; 5=9,6 \times 10^{2} ; 6=1,12 \times 10^{3}$.

Figura 1. Distribuição da contagem para coliformes termotolerantes em queijo-coalho, comercializado no Mercado Central de Aracaju, SE.

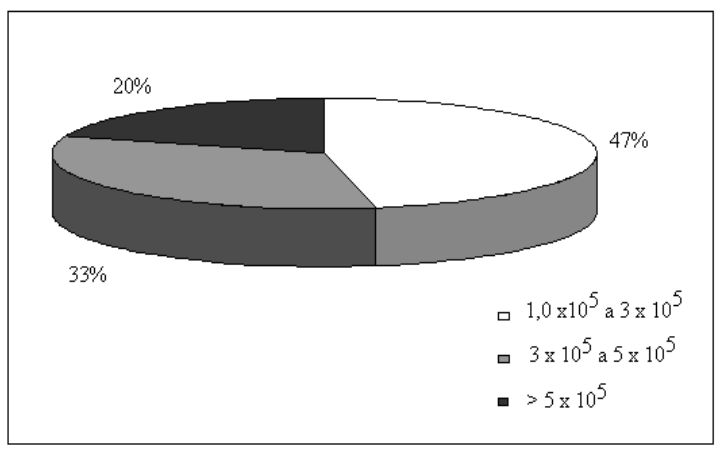

Figura 2. Ocorrência de Staphylococcus aureus em queijo-coalho, comercializado no Mercado Central de Aracaju, SE.

Salmonella spp. foi detectada em $16(26,7 \%)$ das amostras de queijo-coalho analisadas. Feitosa et al. (2003) também observaram Salmonella spp. em $9,1 \%$ das amostras de queijo produzido no Rio Grande do Norte. Por ser potencialmente capaz de provocar infecção de origem alimentar, a presença dessa bactéria no queijo classifica-o como produto impróprio para o consumo. A legislação brasileira recomenda a ausência de Salmonella spp. em alimentos para a venda e consumo. Na confirmação de Salmonela spp., 44 amostras apresentaram testes bioquímicos negativos. Nessas amostras, os microrganismos detectados foram: Escherichia coli (40,0\%), Klebsiella ozaenae (6,7\%), Enterobacter aerogenes (6,7\%), Arizona hinshawii (13,3\%) e Proteus mirabilis (6,7\%). Bulhões e Rossi Júnior (2002) verificaram além dos microrganismos preconizados pela legislação para avaliar a qualidade dos queijos a presença de outros, como as bactérias do gênero Aeromonas, em 51,2\% dos queijos, com concentração de $5,0 \times 10^{3}$ a 4 x $10^{5} \mathrm{UFC} / \mathrm{g}$. Ávila e Gallo (1996) não observaram Salmonella spp. em 19 amostras de queijo-deminas frescal, porém as provas bioquímicas identificaram $46,7 \%$ de Enterobacter spp., 33,3\% de Pseudomonas spp., 13,3\% de E. coli, $13,3 \%$ de Citrobacter sp. e 3,3\% de Hafnea alvei.

Os resultados deste trabalho diferem dos obtidos, em Pernambuco, por Morais (1995), o qual avaliou amostras de queijo-coalho, durante todas as etapas tecnológicas, e não obteve nenhuma amostra positiva, e por Travassos (1998), na Paraíba, em amostras de queijo-coalho artesanal elaborado com leite pasteurizado. Esse resultado confirma a importância de se atender à legislação que preconiza a pasteurização como etapa preliminar de esterilização do leite, entretanto os pequenos produtores, fornecedores de queijocoalho para o Mercado Central de Aracaju, provavelmente não utilizam essa técnica, o que pode ter resultado na contaminação, aliado ao, também provável, manuseio inadequado do alimento durante a comercialização.

\section{CONCLUSÕES}

A elevada população de coliformes totais e termotolerantes detectada indica má qualidade 
higiênico-sanitária dos produtos estudados e a necessidade de capacitação quanto às boas práticas de manipulação e produção de alimentos, além de efetiva fiscalização pelos órgãos competentes. Com base nos padrões microbiológicos vigentes na legislação brasileira, todos os queijos-coalho foram classificados como sendo impróprios para o consumo humano.

\section{REFERÊNCIAS BIBLIOGRÁFICAS}

ASSUMPÇÃO, E.G.; PICCOLI-VALLE, R.H.; HIRSCH, D. et al. Fontes de contaminação por Staphylococcus aureus na linha de processamento de queijo prato. Arq. Bras. Med. Vet. Zootec., v.55, p.366-370, 2003.

ÁVILA, C.R.; GALlO, C.R. Pesquisa de Salmonella spp. em leite cru, leite pasteurizado queijo tipo "minas frescal" comercializados no município de Piracicaba, SP. Sci. Agric., v.53, p.159-163, 1996.

BRASIL. Ministério da Agricultura. Portaria no ${ }^{\circ}$ 146, de 7 de março de 1996. Regulamento Técnico de Identidade e Qualidade de Queijos. Diário Oficial da República Federativa do Brasil, Brasília, DF, 11 mar. 1996, Seção 1, p.3977-3978.

BRASIL. Ministério da Saúde. Agência Nacional de Vigilância Sanitária. Resolução RDC no 12, de 02/01/2001. Regulamento Técnico Sobre os Padrões Microbiológicos para Alimentos. Diário Oficial da República Federativa do Brasil, Brasília, 02/01/2001. p.1-54.

BULHÕES, C.C.C.; ROSSI JUNIOR, O.D. Ocorrência de bactérias do gênero Aeromonas em queijo-de-minas frescal artesanal. Arq. Bras. Med. Vet. Zootec., v.54, p.320-324, 2002.

CABRAL, T.M.A. Coliformes totais e fecais, e Stapylococcus aureus enteropatogênico em queijo de "coalho" comercializado no município de João Pessoa, PB. 1993. 88f. Dissertação (Mestrado) - Universidade Federal da Paraíba, João Pessoa.

CATAO, R.M.R.; CEBALLOS, B.S.O. Pesquisa de. Listeria spp., coliformes totais e fecais e $E$. coli no leite cru e pasteurizado de uma indústria de laticínios, no estado da Paraíba (Brasil). Cienc. Tecnol. Aliment., v.21, p.281-287, 2001.

CAVALCANTE， J.F.M.; ANDRADE， N.J.; FURTADO, M.M. et al. Processamento do queijo coalho regional empregando leite pasteurizado e cultura lática endógena. Cienc. Tecnol. Aliment., v.27, p.205-214, 2007.

CUNHA NETO, A.; SILVA, C.G.M.; STAMFORD, T.L.M. Staphylococcus enterotoxigênicos em alimentos in natura e processados no estado de Pernambuco, Brasil. Cienc. Tecnol. Aliment., v.22, p.263-271, 2002.

DUARTE, D.A.M.; SCHUCH, D.M.T.; SANTOS, S.B. et al. Pesquisa de Listeria monocytogenes e microrganismos indicadores higiênico-sanitários em queijo-coalho produzido e comercializado no estado de Pernambuco. Arq. Inst. Biol., v.72, p.297-302, 2005.

FEITOSA, T.; BORGES, M.F.; NASSU, R.T. et al. Pesquisa de Salmonella sp., Listeria sp. e microrganismos indicadores higiênico-sanitários em queijos produzidos no Estado do Rio Grande do Norte. Cienc. Tecnol. Aliment., v.23, p.162165, 2003.

KONEMAN, E.W.; ALLEN, S.D.; JANDA, W.M. et al. Diagnóstico Microbiológico - Texto y Atlas Color. 5.ed. Buenos Aires: Editorial Medica Panamericana, 1999.

LOGUERCIO, A.P.; ALEIXO, J.A.G. Microbiologia de queijo tipo minas frescal produzido artesanalmente. Cienc. Rural, v.31, p.1063-1067, 2001.

MORAIS, C.M. Processamento artesanal do queijo-coalho de Pernambuco, uma análise de perigo. 1995. 91f. Dissertação (Mestrado) Universidade Federal de Pernambuco, Recife.

PERRY, K.S.P. Queijos: aspectos químicos, bioquímicos e microbiológicos. Quim. Nova, v.27, p.293-300, 2004.

RAPINI, L.S.; TEIXEIRA, J.P.; MARTINS, N.E. et al. Perfil de resistência antimicrobiana de cepas de Staphylococcus sp. isoladas de queijo tipo coalho. Arq. Bras. Med. Vet. Zootec, v.58, p.263-272, 2006.

ROCHA, J.S.; BURITI, F.C.A.; SAAD, S.M.I. Condições de processamento e comercialização de queijo-de-minas frescal. Arq. Bras. Med. Vet. Zootec, v.58, p.263-272, 2006.

SABIONI, J.G.; NASCIMENTO, D.; PEREIRA, J.L. Intoxicação estafilocócica causada por queijo tipo minas em Ouro Preto (MG), 1992. Hig. Alim., v.8, p.22-23, 1994. 
SALOTTI, B.M.; CARVALHO, A.C.F.B.; AMARAL, L.A. et al. Qualidade microbiológica do queijo minas frescal comercializado no município de Jaboticaba, SP, Brasil. Arq. Inst. Biol., v.73, p. 171-175, 2006.

SILVA, N.; JUNQUEIRA, V.C.A.; SILVEIRA, N.F.A. Manual de métodos de análise microbiológica de alimentos. 2.ed. São Paulo: Varela. 1997

TRAVASSOS, A.E.R. Indicadores de contaminação e bactérias lácticas em queijo de coalho processado com coalho extraído do estômago de bovinos adultos. In: CONGRESSO LATINO AMERICANO DE MICROBIOLOGIA E HIGIENE DE ALIMENTOS, 1998, Águas de Lindóia. Anais... Águas de Lindóia: SBM, 1998.

VANDERZANT, C.; SPLITTSTOESSER, D.F. Compendium for the microbiological examination of foods. 3.ed. Washington, DC: American Public Health Association, 1992. 